\title{
Манифест прикладного конструктивизма
}

\author{
Н. Н. НЕПЕЙВОДА, А. П. БЕЛЬТЮКОВ
}

ABstraCt. Manifest of constructivism reborned. This constructive concept is in some extents more liberal and in some extents more strict than traditional ones. It is intended to join together best sides of intuitionism and Soviet constructivism and to apply the to practical problems of informatics and other domains. Main its peculiarities are:

1. Intensive use of ignorance as a positive factor.

2. Strict discrimination of constructive and descriptive reasoning both necessary for a good theory.

3. Admission of Hilbert's program core statements.

4. Admission of actual infinity for purely descriptive considerations.

5. Transition to real constructability for many constructive considerations.

6. Dependence of constructive logics from admitted variant of constructability. Your main value dictates your logic.

7. Modestly platonistic philosophy. Ideal notions are not invented, they are discovered, but human cannot reach any absolute idea.

8. Scientific anti-monopolism and anti-globalism. Human cannot invent something absolute.

9. Anti-relativism. We are to choose the best tool for our problem and quality of its solution is determined mainly by quality of means applied. There is no «freedom of choice» for truly creative and responsible subject. His/her decisions are forced by well understood necessity.

Ключевые слова: конструктивизм, прикладной конструктивизм, информатика

1. Настала пора возрождать конструктивное направление в математике, некогда составлявшее одну из самых славных частей советской математической школы.

2. При этом необходимо сразу же придать данному направлению прикладной характер, что планировал А. А. Марков, 
но не смог из-за недостаточного развития тогдашней информатики.

3. Прикладной конструктивизм может развиваться лишь на стыке двух наук: математики и логики - и трех областей знания: математики, информатики и философии.

4. Основными методологическими принципами прикладного конструктивизма являются следующие.

(а) Прикладной конструктивизм должен соединять лучшие стороны советского конструктивизма, альтернативных конструктивных направлений, интуиционизма и классики.

(b) Необходимо строго соблюдать концептуальную целостность. Главный враг хорошей концепции - лишние возможности.

(c) В области прикладных теорий принимаются абстракции отождествления, различные варианты реальной осуществимости и потенциальной осуществимости.

(d) При этом потенциальная осуществимость рассматривается как идеальный предельный случай реальной осуществимости.

(е) Нельзя идти слишком прямыми путями, необходимо искать обходные. Путь к конструктивным решениям может пролегать через идеальные конструкции.

(f) Из-за парадокса изобретателя красивую и полезную теорию не построишь без идеальных объектов. Поэтому строго различаются конструктивные и дескриптивные области, конструктивные и дескриптивные понятия и части выводов.

(g) Допустимо использование абстракции актуальной бесконечности в дескриптивных областях и для дескриптивных понятий, для которых не требуется получение конструктивных методов (например, в теории моделей для конструктивной математики).

(h) Логика дескриптивной математики, логика потенциальной осуществимости и логики реальной осуществимости - разные. 
(i) Потенциальная осуществимость рассматривается как средство, которым получают чистые теоремы. Если эффективность решений, достигаемых чистыми методами, недостаточна, следует перейти к более высокой степени конструктивности: к различным формам абстракции реальной осуществимости и различным ее сложностным классам.

(j) Реальная осуществимость различна в зависимости от главного принимаемого во внимание ресурса: времени, денег, обратимости действий и т. п. Реальные осуществимости могут образовывать иерархии в зависимости от классов ограничений на используемые ресурсы.

(k) В связи с вышеизложенным, полностью отвергается попытка унифицировать все и вся и монополизм одной из парадигм. Каждая из них хороша на своем и только на своем месте.

(1) Самый большой недостаток - эклектизм, смешение в одном месте разных парадигм.

(m) Это не препятствует осознанному и критическому использованию в одной из парадигм результатов другой как вещей в себе.

(n) Построение объектов не является единственной или главной целью конструктивизма. Его главная задача как идеальной математической теории - анализ методов построений.

(о) Осознанное незнание - один из наиболее мощных видов знания. Нельзя скатываться к иллюзии всезнания и призраку познаваемости всего и вся.

5. Основными математическими принципами прикладного конструктивизма являются следующие.

(а) Использование неклассических логик и неклассических теорий для анализа понятий реальной и потенциальной осуществимости. 
(b) Ориентация с самого начала на нечисленную математику и абстрактные объекты, что соответствует и нынешней практике информатики.

(с) Использование в качестве основной абстрактной дескриптивной теории теории категорий.

(d) Отказ от попыток переписать существующую математическую традицию в новых терминах, поскольку ныне это осознано как одна из основных стратегических ошибок конструктивных направлений. Тем не менее, приветствуется перестройка некоторых разделов традиционной конструктивной математики в терминах различных видов реальной вычислимости.

(е) Мирное сосуществование с классической математикой на принципах взаимного признания и взаимообогащения, отказ от всяких попыток глобализации своих концепций и вместе с тем непримиримая война против глобалистских замашек классики.

(f) Четкое осознание того, что универсальные решения никуда не годятся на практике и что конструктивизм средство поиска хороших решений именно для данной цели в данной обстановке.

(g) Ориентация не на полноту теорий, а на их адекватность.

(h) Полный отказ в связи с этим от критики по принципу «У Вас нет того-то». Введение в математические обычаи критики по принципу «А зачем у Вас здесь есть это? Нельзя бы было без него обойтись?».

(i) Понимание того, что не сам результат ценен, а его доказательство.

(j) Четкое понимание того, что, прыгая по верхам, ничего серьезного не получишь. Действительно полезная теория очень трудна. Действительно полезные результаты получаются после того, как пройдет пора первых легких успехов, и с громадным трудом удастся либо пробиться через вторую, намного более мощную, линию обороны, либо обойти ее по болотистым и коварным тропкам. 
(k) В связи с этим поддержка тенденции фундаментализации математического и информатического образования и война с попытками превратить обучение в натаскивание.

(1) Четкое понимание того, что каждая действительно глубокая математическая концепция (например, действительные числа) имеет множество измерений, что фиксированных объектов в математике (кроме простых финитных структур) нет вообще.

(m) Показ в связи с этим каждого результата в контексте не только положительных, но и отрицательных примеров применения.

(n) Четкое понимание того, что основная сила математики - не конструктивные, а негативные результаты, и формирование у обучающихся привычки искать во всех нетривиальных случаях коварные ловушки.

6. Основные принципы взаимодействия прикладного конструктивизма с информатикой следующие.

(a) Полный отказ от задач типа «обосновать такую-то конструкцию». За благословением нужно обращаться к священникам, а не к ученым.

(b) Безжалостный критический анализ вместе с максимально доброжелательным истолкованием его результатов. Основная польза конструктивизма - вовремя расставлять красные флажки там, где привыкли безоглядно рваться вперед.

(с) Постоянные переходы между формальным и содержательным и между различными формализмами для целей многостороннего комплексного охвата ситуации.

(d) Использование в каждом месте адекватных для данной ситуации средств.

(е) Перепроверка полученного одним методом другим методом, в том числе формального - содержательным, содержательного - формальным. 
(f) Накопление для каждого важного понятия как можно большего количества эквивалентных математических представлений, потому что они на практике дают различные решения.

(g) Полный отказ от следования моде.

(h) Полный отказ от отождествления «нового» и «хорошего». Новое скорее то, что является заведомо недоделанным и подозрительным.

(i) При всем этом максимальное следование принципам и методам творческого мышления.

(j) Развитие лучших сторон русского негативного мышления, поскольку именно оно позволяет органически слить все вышесказанное. 